\title{
Article \\ Doxorubicin Impairs Smooth Muscle Cell Contraction: Novel Insights in Vascular Toxicity
}

\author{
Matthias Bosman ${ }^{1}$ * , Dustin N. Krüger ${ }^{1}$, Kasper Favere ${ }^{1,2,3,4}{ }^{\mathbb{D}}$, Callan D. Wesley ${ }^{1}$, Cédric H. G. Neutel ${ }^{1}$ (D) \\ Birgit Van Asbroeck ${ }^{5}$, Owen R. Diebels ${ }^{1}$, Bart Faes ${ }^{1}$, Timen J. Schenk ${ }^{1}$, Wim Martinet ${ }^{1}{ }^{1}$, \\ Guido R. Y. De Meyer ${ }^{1}$ (D), Emeline M. Van Craenenbroeck ${ }^{2,4}$ and Pieter-Jan D. F. Guns ${ }^{1}(\mathbb{D}$
}

1 Laboratory of Physiopharmacology, Faculty of Medicine and Health Sciences, Faculty of Pharmaceutical, Biomedical and Veterinary Sciences, Campus Drie Eiken, University of Antwerp, Universiteitsplein 1, B-2610 Antwerp, Belgium; dustin.kruger@uantwerpen.be (D.N.K.); kasper.favere@uantwerpen.be (K.F.); callan.wesley@uantwerpen.be (C.D.W.); cedric.neutel@uantwerpen.be (C.H.G.N.); owen.diebels@student.uantwerpen.be (O.R.D.); bart.faes@student.uantwerpen.be (B.F.); timen.schenk@student.uantwerpen.be (T.J.S.); wim.martinet@uantwerpen.be (W.M.); guido.demeyer@uantwerpen.be (G.R.Y.D.M.); pieter-jan.guns@uantwerpen.be (P.-J.D.F.G.)

2 Research Group Cardiovascular Diseases, University of Antwerp, B-2610 Antwerp, Belgium; emeline.vancraenenbroeck@uantwerpen.be

3 Department of Internal Medicine, Faculty of Medicine and Health Sciences, Ghent University, C. Heymanslaan 10, B-9000 Ghent, Belgium

4 Department of Cardiology, Antwerp University Hospital (UZA), Drie Eikenstraat 655, B-2650 Edegem, Belgium

check for updates

Citation: Bosman, M.; Krüger, D.N.; Favere, K.; Wesley, C.D.; Neutel, C.H.G.; Van Asbroeck, B.; Diebels, O.R.; Faes, B.; Schenk, T.J.; Martinet, W.; et al. Doxorubicin Impairs Smooth Muscle Cell Contraction: Novel Insights in Vascular Toxicity. Int. J. Mol. Sci. 2021, 22, 12812. https://doi.org/10.3390/ ijms222312812

Academic Editor: Ioanna Andreadou

Received: 27 August 2021

Accepted: 23 November 2021

Published: 26 November 2021

Publisher's Note: MDPI stays neutral with regard to jurisdictional claims in published maps and institutional affiliations.

Copyright: (C) 2021 by the authors. Licensee MDPI, Basel, Switzerland. This article is an open access article distributed under the terms and conditions of the Creative Commons Attribution (CC BY) license (https:/ / creativecommons.org/licenses/by/ $4.0 /)$.
5 Research Group MOVANT, Department of Rehabilitation Sciences and Physiotherapy, Faculty of Medicine and Health Sciences, Campus Drie Eiken, University of Antwerp, Universiteitsplein 1, B-2610 Antwerp, Belgium; birgit.vanasbroeck@uantwerpen.be

* Correspondence: matthias.bosman@uantwerpen.be; Tel.: +32-3-265-8950

Abstract: Clinical and animal studies have demonstrated that chemotherapeutic doxorubicin (DOX) increases arterial stiffness, a predictor of cardiovascular risk. Despite consensus about DOX-impaired endothelium-dependent vasodilation as a contributing mechanism, some studies have reported conflicting results on vascular smooth muscle cell (VSMC) function after DOX treatment. The present study aimed to investigate the effects of DOX on VSMC function. To this end, mice received a single injection of $4 \mathrm{mg}$ DOX $/ \mathrm{kg}$, or mouse aortic segments were treated ex vivo with $1 \mu \mathrm{M}$ DOX, followed by vascular reactivity evaluation $16 \mathrm{~h}$ later. Phenylephrine (PE)-induced VSMC contraction was decreased after DOX treatment. DOX did not affect the transient PE contraction dependent on $\mathrm{Ca}^{2+}$ release from the sarcoplasmic reticulum $\left(0 \mathrm{mM} \mathrm{Ca}^{2+}\right)$, but it reduced the subsequent tonic phase characterised by $\mathrm{Ca}^{2+}$ influx. These findings were supported by similar angiotensin II and attenuated endothelin-1 contractions. The involvement of voltage-gated $\mathrm{Ca}^{2+}$ channels in DOX-decreased contraction was excluded by using levcromakalim and diltiazem in PE-induced contraction and corroborated by similar $\mathrm{K}^{+}$and serotonin contractions. Despite the evaluation of multiple blockers of transient receptor potential channels, the exact mechanism for DOX-decreased VSMC contraction remains elusive. Surprisingly, DOX reduced ex vivo but not in vivo arterial stiffness, highlighting the importance of appropriate timing for evaluating arterial stiffness in DOX-treated patients.

Keywords: doxorubicin; cardio-oncology; arterial stiffness; endothelial dysfunction; vascular smooth muscle cell contraction; non-selective cation channel

\section{Introduction}

The anthracycline doxorubicin (DOX) is one of the most efficacious chemotherapeutic drugs for the treatment of a wide array of cancers [1]. However, DOX treatment has been associated with development of cardiotoxicity and eventually heart failure, which limits its clinical use [2-6]. While DOX-induced cardiotoxicity has been extensively investigated (reviewed elsewhere) [7], the toxic effects of DOX on the vasculature have been less considered. 
Epidemiological studies point towards accelerated vascular ageing in childhood cancer survivors, as evidenced by a higher incidence of atherosclerosis and hypertension [8-10]. Moreover, several studies have demonstrated that DOX increases arterial stiffness in cancer patients, both during and after treatment [11-14]. Arterial stiffness is associated with an increased risk of cardiovascular events and mortality, as it impacts arterial pressure, cardiac performance and perfusion [15-17].

Previously, it was shown that DOX impairs flow-mediated vasodilation in the brachial artery in patients shortly after DOX treatment, often referred to as endothelial dysfunction [18]. In addition, our research group demonstrated that 2 weeks of DOX administration to mice ( $4 \mathrm{mg} / \mathrm{kg}$ / week) acutely impaired endothelium-dependent vasodilation and consequently increased vascular tone, thereby actively augmenting arterial stiffness [19]. We, and others, identified endothelial cell loss and reduced endothelial nitric oxide synthase (eNOS) levels as potential mechanisms contributing to impaired endothelial function after DOX treatment $[19,20]$. Other studies have reported that DOX may cause uncoupling of eNOS, which is characterised by increased superoxide formation instead of nitric oxide production, thereby contributing to reactive oxygen species (ROS) generation [21,22].

Apart from the widely accepted toxic impact of DOX on endothelial cell (EC) function, DOX also affects vascular smooth muscle cell (VSMC) function [23-25]. There have been conflicting reports about the role of DOX in the alteration of VSMC reactivity. Gibson et al. reported decreased VSMC contraction in rat thoracic aorta rings $24 \mathrm{~h}$ after DOX treatment $(15 \mathrm{mg} / \mathrm{kg})$ [23]. Similarly, Olukman et al. demonstrated that DOX $(20 \mathrm{mg} / \mathrm{kg})$ attenuated VSMC contraction in rat aortic segments 1 week after administration [24]. Conversely, Shen et al. described increased VSMC contraction in mouse aortic rings after ex vivo DOX treatment $(100 \mu \mathrm{M})$, which was attributable to increased $\mathrm{Ca}^{2+}$ release from the sarcoplasmic reticulum and $\mathrm{Ca}^{2+}$ entry in VSMCs [25]. In our previous study, we did not observe any direct effects of 2 weeks DOX treatment on VSMC contraction [19]. Hence, the exact effects of DOX on modulation of VSMC function remain unclear and may be dependent upon the dose or treatment protocol.

In this study, we aimed to investigate the effects of a single dose of DOX on VSMC function, including its contribution to arterial stiffness. A secondary goal was to evaluate whether the acute effects of DOX could be studied ex vivo in aortic rings. Such an ex vivo platform holds potential for mechanistic studies, as well as for future drug screening.

\section{Results}

\subsection{A Single Dose of DOX Impairs VSMC Contraction and Endothelium-Dependent Vasodilation}

There was a decrease in phenylephrine (PE)-induced contraction $16 \mathrm{~h}$ after in vivo DOX administration (Figure 1A). The PE-elicited contraction response, which comprises an initial transient and a subsequent tonic phase [26], was further investigated. DOX reduced the tonic but not the transient contraction in aortic segments after addition of $2 \mu \mathrm{M}$ PE (Figure 1B).

Since the tonic contraction phase is dependent on $\mathrm{Ca}^{2+}$ influx [26], determining the increase in contraction force $(\Delta)$ at different time points offers an estimate of the effectiveness of $\mathrm{Ca}^{2+}$ influx in VSMCs. Here, we calculated the increase in force $(\Delta)$ by subtracting the force at $800 \mathrm{~s}$ from the force at $100 \mathrm{~s}$ during the PE-elicited contraction response. This increase in contraction force $(\Delta)$ was lower in the DOX-treated group compared with the vehicle-treated group (Figure 1C), which suggests that DOX impairs $\mathrm{Ca}^{2+}$ influx.

The contraction force remained lower in the DOX-treated group in the presence of $\mathrm{N \omega}$ nitro-L-arginine methyl ester (L-NAME) (Figure 1D). Of note, the PE contraction in panel $\mathrm{D}$ is the maximal amplitude of panel $\mathrm{B}$, and these contraction amplitudes are higher than in panel A due to a decrease of basal nitric oxide (NO) over time [27]. Further, impaired acetylcholine (ACh)-induced endothelium-dependent relaxation was observed after DOX, while diethylamine NONOate (DEANO)-induced endothelium-independent relaxation was not affected (Figure 1E). These results suggest that DOX decreases VSMC contraction through a VSMC-specific mechanism. 


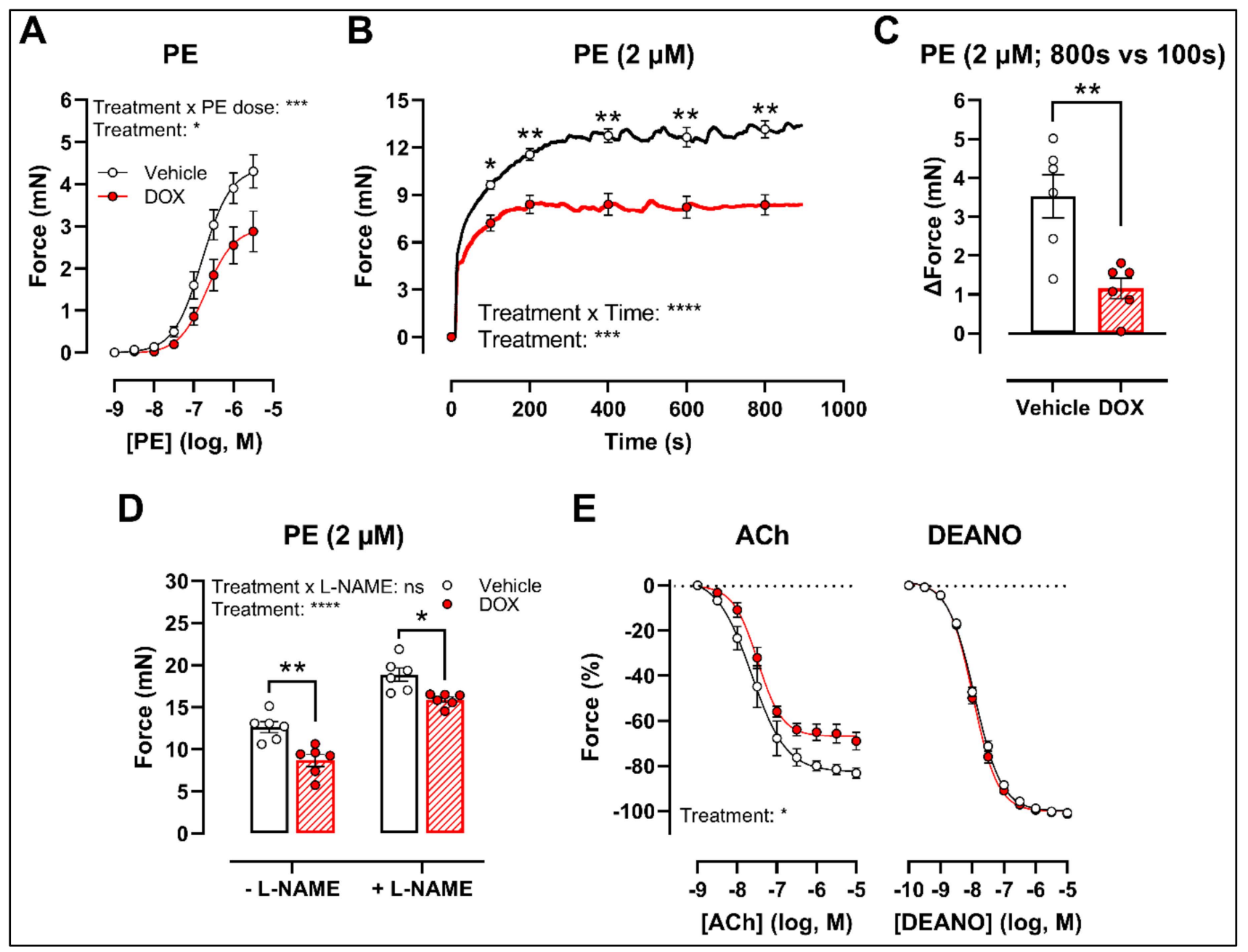

Figure 1. VSMC contraction and relaxation in aortic segments, $16 \mathrm{~h}$ after in vivo DOX administration. PE-induced contraction was decreased in aortic segments after in vivo DOX treatment (A). The PE-elicited contraction response was reduced after DOX treatment, which suggests perturbed tonic contraction (B). The increase in force between $800 \mathrm{~s}$ and $100 \mathrm{~s}$ was lower in the DOX group, indicating that DOX impairs $\mathrm{Ca}^{2+}$ influx $(\mathbf{C})$. The DOX-induced reduction in contraction persisted under L-NAME conditions (D). DOX impaired ACh-induced relaxation, but relaxation of aortic segments in response to DEANO did not change (E). For (A,B,E), repeated measures two-way ANOVA with Šidàk's multiple comparisons test. For (C), unpaired $t$-test. For (D), two-way ANOVA with Tukey's multiple comparisons test. $*, * *, * * *, * * * * 0<0.05,0.01,0.001,0.0001 ; n=6$ for each group.

\subsection{Ex Vivo Incubation of Aortic Rings with DOX Leads to Reduced VSMC Contraction and Impaired Endothelium-Dependent Relaxation}

To develop a drug testing platform for studying acute effects of DOX and to corroborate the in vivo DOX treatment findings, isolated aortic segments were isolated from mice and subsequently treated with DOX $(1 \mu \mathrm{M})$ ex vivo for $16 \mathrm{~h}$. Similar results were obtained under these experimental conditions. More specifically, PE-induced contraction was reduced after DOX treatment in a PE concentration response curve (Figure 2A) and contraction-over-time curve (Figure $2 \mathrm{~B})$. The increase in force $(\Delta)$ was lower for DOX-treated aortic segments compared with the vehicle group (Figure $2 \mathrm{C}$ ). Under L-NAME conditions, the contraction remained decreased in the DOX group (Figure 2D), and there was impaired ACh-induced relaxation and unaltered DEANO-induced relaxation (Figure 2E). 


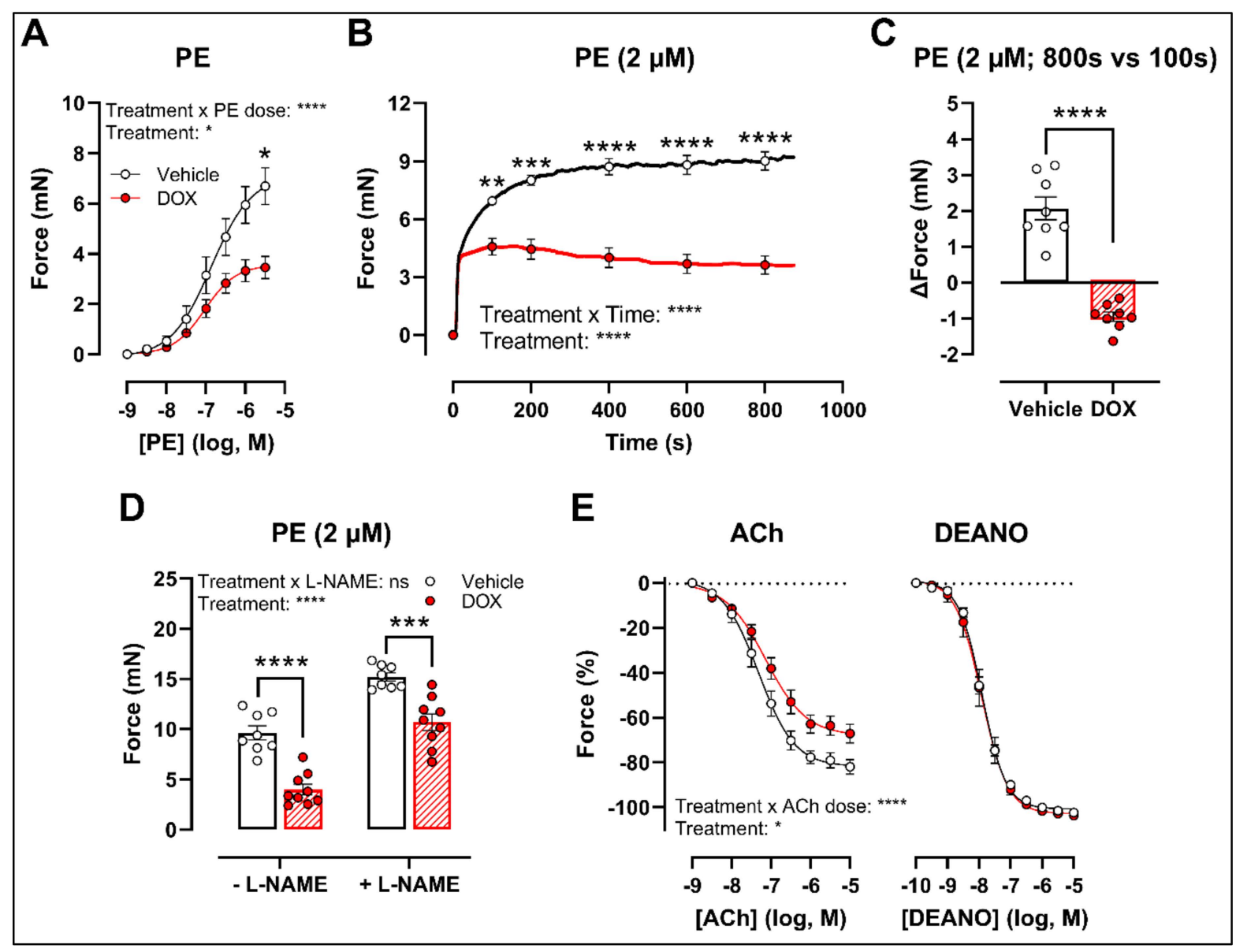

Figure 2. VSMC contraction and relaxation in aortic segments after $16 \mathrm{~h}$ of ex vivo DOX treatment. Following $16 \mathrm{~h}$ of ex vivo DOX treatment, VSMC contraction was decreased in response to PE (A,B). In the DOX-treated aortic segments, there was a lower increase in force between $800 \mathrm{~s}$ and $100 \mathrm{~s}(\mathrm{C})$. The DOX-induced decrease in contraction was still observed in the presence of L-NAME (D). ACh-induced relaxation, but not DEANO-induced relaxation, was impaired in response to DOX (E). For (A,B,E), repeated measures two-way ANOVA with Šidàk's multiple comparisons test. For (C), unpaired $t$-test. For (D), two-way ANOVA with Tukey's multiple comparisons test. *, *****, ****$p<0.05,0.01,0.001,0.0001 ; n=8$ for vehicle group and $n=9$ for DOX group.

2.3. DOX Does Not Modulate $\mathrm{Ca}^{2+}$ Release from the Sarcoplasmic Reticulum or $\mathrm{Ca}^{2+}$ Influx through Voltage-Gated Calcium Channels

To further investigate the molecular mechanisms of DOX-reduced VSMC contraction, the PE contraction $(2 \mu \mathrm{M})$ was repeated under $0 \mathrm{mM} \mathrm{Ca}^{2+}$ Krebs Ringer and $\mathrm{CaCl}_{2}(3.5 \mathrm{mM}$ $\mathrm{Ca}^{2+}$ ) conditions to specifically evaluate the transient contraction phase, caused by $\mathrm{Ca}^{2+}$ release from the sarcoplasmic reticulum, and the tonic contraction phase, characterised by VGCC- and NSCC-mediated $\mathrm{Ca}^{2+}$ entry, respectively. To avoid the possible influence of NO, experiments were performed under L-NAME conditions. Contraction mediated by $\mathrm{Ca}^{2+}$ release from the sarcoplasmic reticulum and decline in contraction due to $\mathrm{Ca}^{2+}$ uptake and $\mathrm{Ca}^{2+}$ efflux were not altered in response to DOX (Figure 3A). Upon addition of $3.5 \mathrm{mM}$ $\mathrm{Ca}^{2+}$, thereby promoting $\mathrm{Ca}^{2+}$ entry through voltage-gated calcium channels (VGCCs) and non-selective cation channels (NSCCs), the resulting VSMC contraction was lower in the DOX-treated group compared with the vehicle group (Figure 3B). Subsequent addition of the VGCC blocker diltiazem $(35 \mu \mathrm{M})$ revealed similar relaxation between the vehicle- and DOX-treated aortic segments (Figure 3C). VSMC contraction, elicited by different doses of $\mathrm{K}^{+}(10,20,30,40$ and $50 \mathrm{mM})$, was not altered after DOX treatment (Figure 3D). Moreover, incubation of aortic segments with the VGCC deactivator levcromakalim $(1 \mu \mathrm{M})$, prior to addition of PE, resulted again in decreased tonic contraction in the DOX-treated group 
compared with the vehicle group (Figure 3E). These results suggest that DOX does not decrease VSMC contraction through molecular mechanisms responsible for intracellular $\mathrm{Ca}^{2+}$ release or $\mathrm{Ca}^{2+}$ uptake, $\mathrm{Ca}^{2+}$ efflux and VGCC-mediated $\mathrm{Ca}^{2+}$ entry.

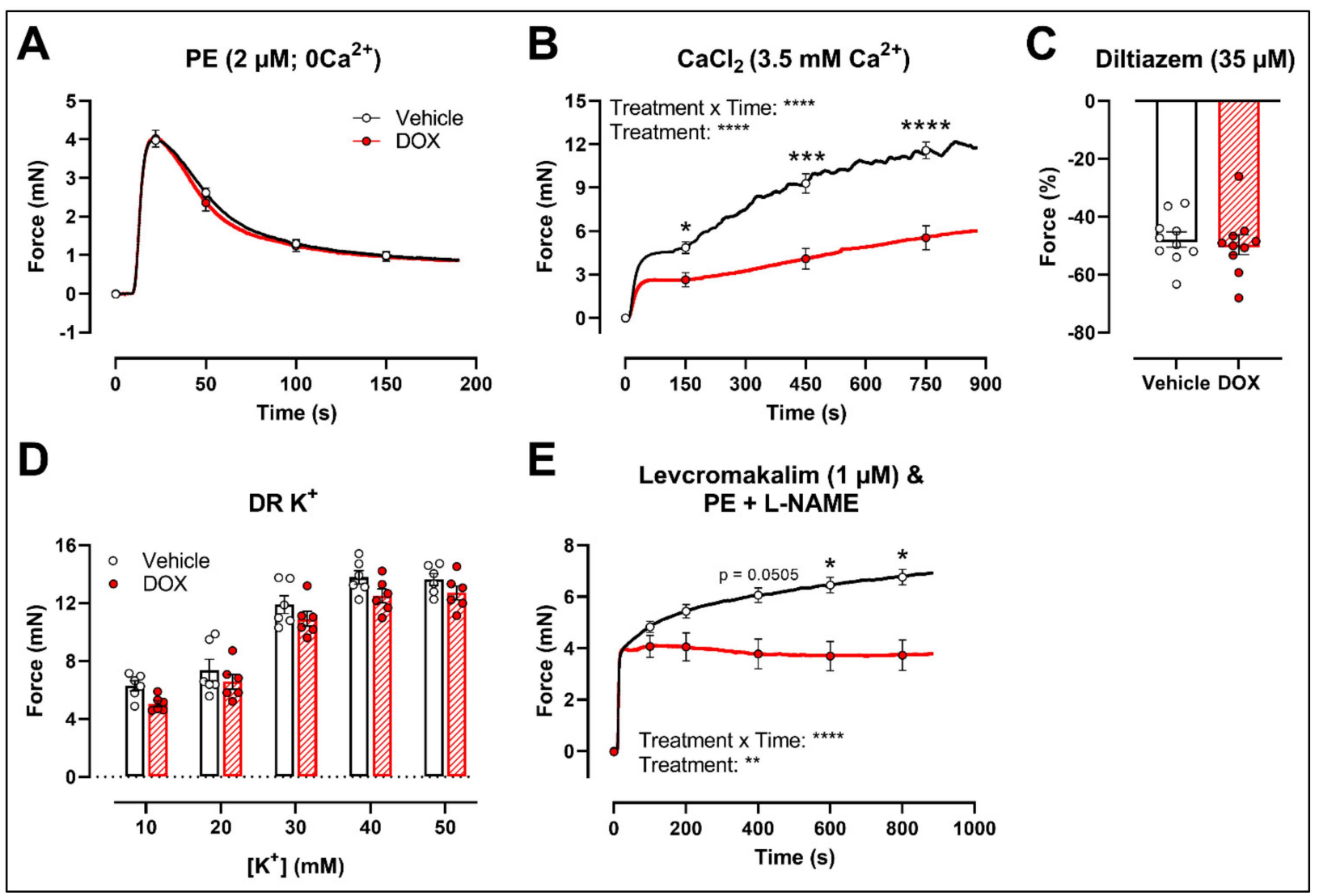

Figure 3. Contraction of aortic segments mediated by $\mathrm{Ca}^{2+}$ release from the sarcoplasmic reticulum and $\mathrm{Ca}^{2+}$ entry through VGCCs and NSCCs after $16 \mathrm{~h}$ of ex vivo DOX treatment. (A) Contraction through $\mathrm{Ca}^{2+}$ release from the sarcoplasmic reticulum in response to PE $(2 \mu \mathrm{M})$ in the absence of extracellular $\mathrm{Ca}^{2+}\left(0 \mathrm{mM} \mathrm{Ca}^{2+}\right)$. (B) Addition of $3.5 \mathrm{mM} \mathrm{Ca}^{2+}$ after $0 \mathrm{mM} \mathrm{Ca}^{2+}$ PE-elicited contraction. (C) Addition of $35 \mu \mathrm{M}$ diltiazem following stable $\mathrm{CaCl}_{2}$-mediated contraction. (D) Dose-response of $\mathrm{K}^{+}$-elicited contraction (10, 20, 30, 40 and $50 \mathrm{mM}$ ). (E) PE-induced contraction (with L-NAME) under levcromakalim $(1 \mu \mathrm{M})$. DOX did not change contraction through $\mathrm{Ca}^{2+}$ release from the sarcoplasmic reticulum, nor $\mathrm{Ca}^{2+}$ uptake and $\mathrm{Ca}^{2+}$ efflux after $16 \mathrm{~h}$ of ex vivo DOX treatment (A), but VSMC contraction was decreased in the DOX-treated group after $\mathrm{CaCl}_{2}$ addition (B). There was no difference in VSMC relaxation between the groups after blocking of VGCCs with diltiazem $(\mathbf{C})$, nor in the contraction magnitude in response to different $\mathrm{K}^{+}$doses (D). DOX decreased PE-induced contraction (with L-NAME) in the presence of levcromakalim (E). For $(\mathbf{A}, \mathbf{B}, \mathbf{D}, \mathbf{E})$, repeated measures two-way ANOVA with Šidàk's multiple comparisons test. For (C), unpaired $t$-test. ${ }^{*}{ }^{* * *},{ }^{* * * *} p<0.05,0.001,0.0001 ; p>0.05$ in $(\mathbf{A}, \mathbf{C}, \mathbf{D}) ;(\mathbf{A}-\mathbf{C}) n=10$ in each group; $(\mathbf{D}, \mathbf{E}) n=6$ in each group.

Another possibility is that DOX affects NSCC-mediated contraction instead. Accordingly, further experiments were performed using several pharmacological agents blocking a variety of NSCCs, such as tranilast, SKF-96365, 2-aminoethoxydiphenyl borinate (2-APB) and 9-phenantrol. To avoid any possible inhibitory effect of NO on VGCCs and NSCCs, the following experiments were performed under L-NAME conditions.

Similar to the decrease in PE-elicited contraction (with L-NAME) under levcromakalim, DOX reduced the PE-induced VSMC contraction $(2 \mu \mathrm{M})$ in aortic segments preincubated with diltiazem $(35 \mu \mathrm{M})$ (Figure $4 \mathrm{~A})$. Subsequent addition of tranilast $(100 \mu \mathrm{M})$, SKF-96365 $(10 \mu \mathrm{M}), 2-\mathrm{APB}(20 \mu \mathrm{M})$ or 9-phenantrol $(1 \mu \mathrm{M})$ resulted in a decline in VSMC contraction, which did not differ in absolute values (Figure 4B) but was higher in the DOX-treated group when expressed relative to its preceding contraction (Figure 4C). 


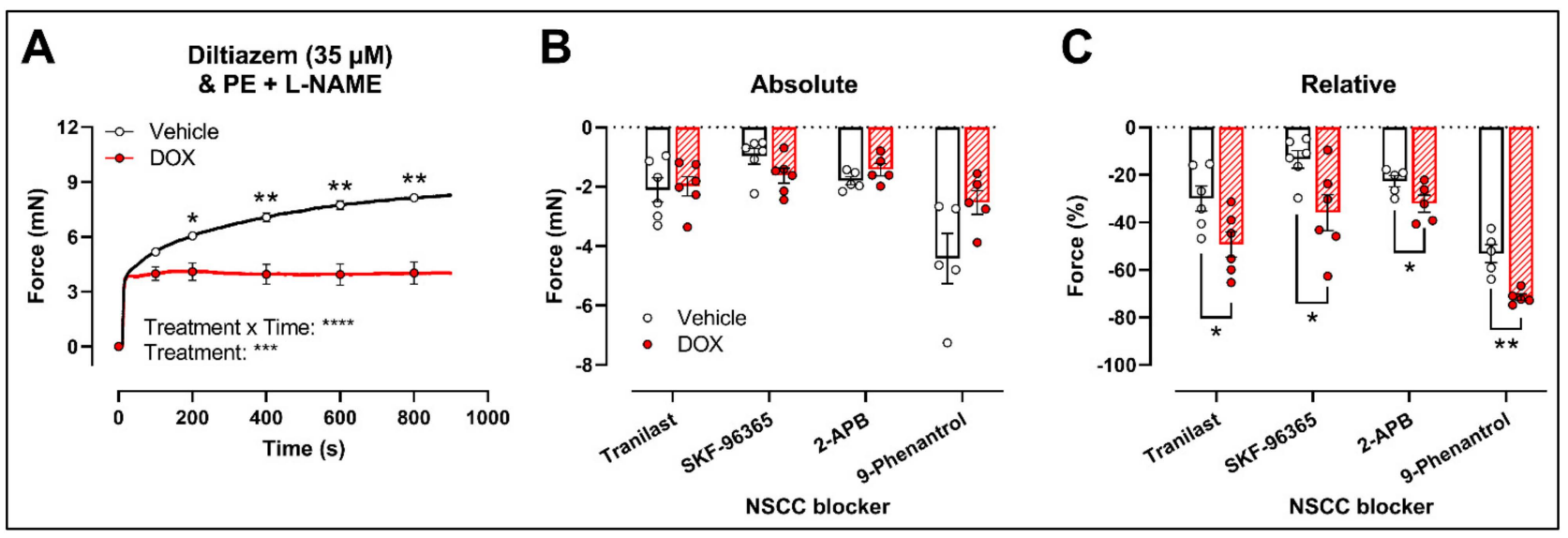

Figure 4. Evaluation of the involvement of members of the NSCC family in decreased PE-induced contraction in aortic segments after $16 \mathrm{~h}$ of ex vivo DOX treatment. (A) PE-induced contraction ( $2 \mu \mathrm{M}$, with L-NAME) under diltiazem (35 $\mu \mathrm{M})$. $(B, C)$ Absolute and relative decline in PE-induced contraction (with L-NAME and diltiazem) under different NSCC-blocker conditions. DOX decreased PE-induced contraction (with L-NAME) in the presence of diltiazem (A). In addition, the DOX-treated group did not display a significant change in VSMC contraction in absolute values (B) but showed a greater decline in VSMC contraction when expressed relative to its preceding contraction magnitude under tranilast $(100 \mu \mathrm{M})$, SKF-96365 $(10 \mu \mathrm{M}), 2$-APB $(20 \mu \mathrm{M})$ and 9-phenantrol $(1 \mu \mathrm{M})(\mathrm{C})$. For $(\mathrm{A})$, repeated measures two-way ANOVA with Šidàk's multiple comparisons test. For $(\mathbf{B}, \mathbf{C})$, unpaired $t$-test for each NSCC blocking condition. ${ }^{*}, * *, * * *, * * * *<0.05,0.01,0.001$, $0.0001 ; p>0.05$ in (B); $n=6$ in each group.

Finally, to evaluate whether the decrease in VSMC contraction after DOX treatment was specific for the PE-elicited response, additional contraction agonists were used. DOXtreated aortic segments showed decreased VSMC contraction in response to $0.25 \mu \mathrm{M}$ endothelin-1 (Figure 5A) but not after $2 \mu \mathrm{M}$ angiotensin II (Figure 5B), $2 \mu \mathrm{M}$ serotonin (Figure 5C) and $50 \mathrm{mM} \mathrm{K}^{+}$(Figure 5D) stimulation.

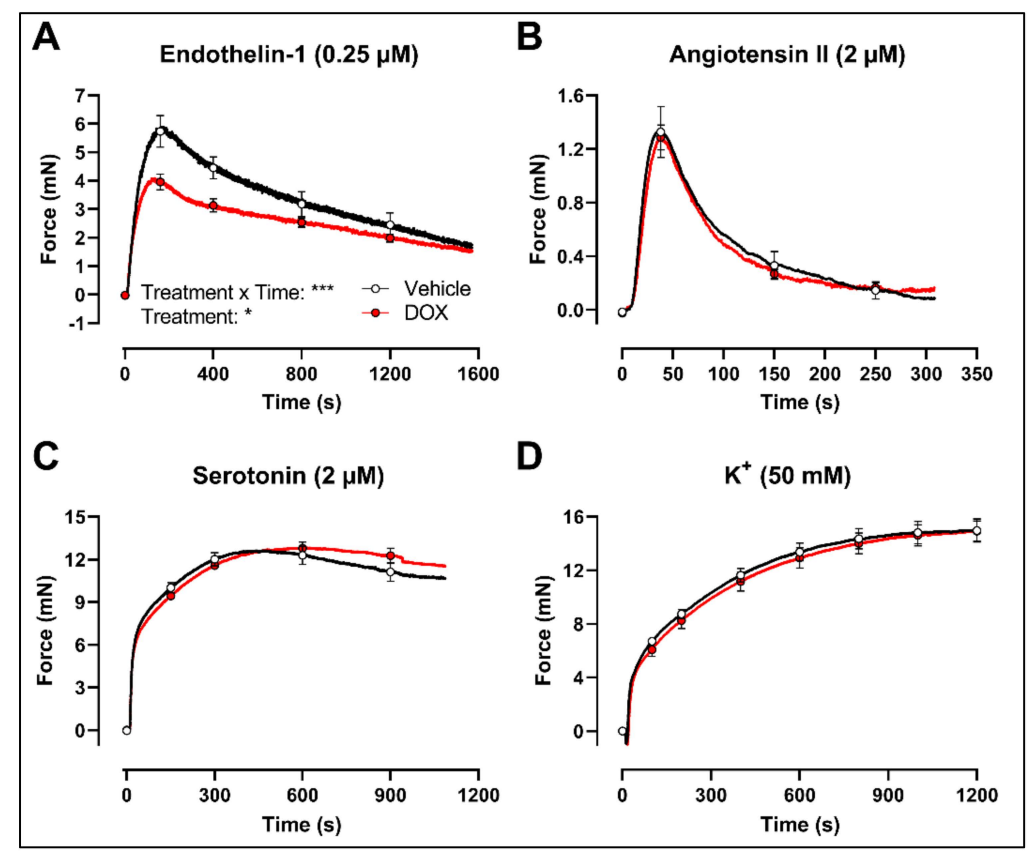

Figure 5. Contraction of aortic segments with endothelin-1, angiotensin II, serotonin and $\mathrm{K}^{+}$after 16 $\mathrm{h}$ of ex vivo DOX treatment. DOX decreased VSMC contraction in response to $0.25 \mu \mathrm{M}$ endothelin- 1 (A) but not after stimulation with $2 \mu \mathrm{M}$ angiotensin II (B), $2 \mu \mathrm{M}$ serotonin (C) and $50 \mathrm{mM} \mathrm{K}^{+}$(D). For (A-D), repeated measures two-way ANOVA with Šidàk's multiple comparisons test. ${ }^{*}, * * *<<0.05$, $0.001 ; p>0.05$ in (B-D); For (A-C), $n=6$ in each group; for (D), $n=10$ in each group. 


\subsection{A Single Dose of DOX Decreases Ex Vivo Arterial Stiffness but Not In Vivo Arterial Stiffness and Blood Pressure}

The possible translation of the aforementioned findings to arterial stiffness was investigated by evaluation of ex vivo and in vivo arterial stiffness.

The ROTSAC set-up was used for ex vivo evaluation of arterial stiffness, $16 \mathrm{~h}$ after in vivo DOX administration $(4 \mathrm{mg} / \mathrm{kg}$ ). Under Krebs Ringer conditions, the Peterson's modulus (Ep), a measure for arterial stiffness, was lower in the DOX group, especially at higher pressures (Figure 6A). This effect was less pronounced in the presence of PE combined with L-NAME (Figure 6B). In the presence of DEANO, which removes VSMC tonus, DOX decreased Ep (Figure 6C) in a pressure-dependent way.

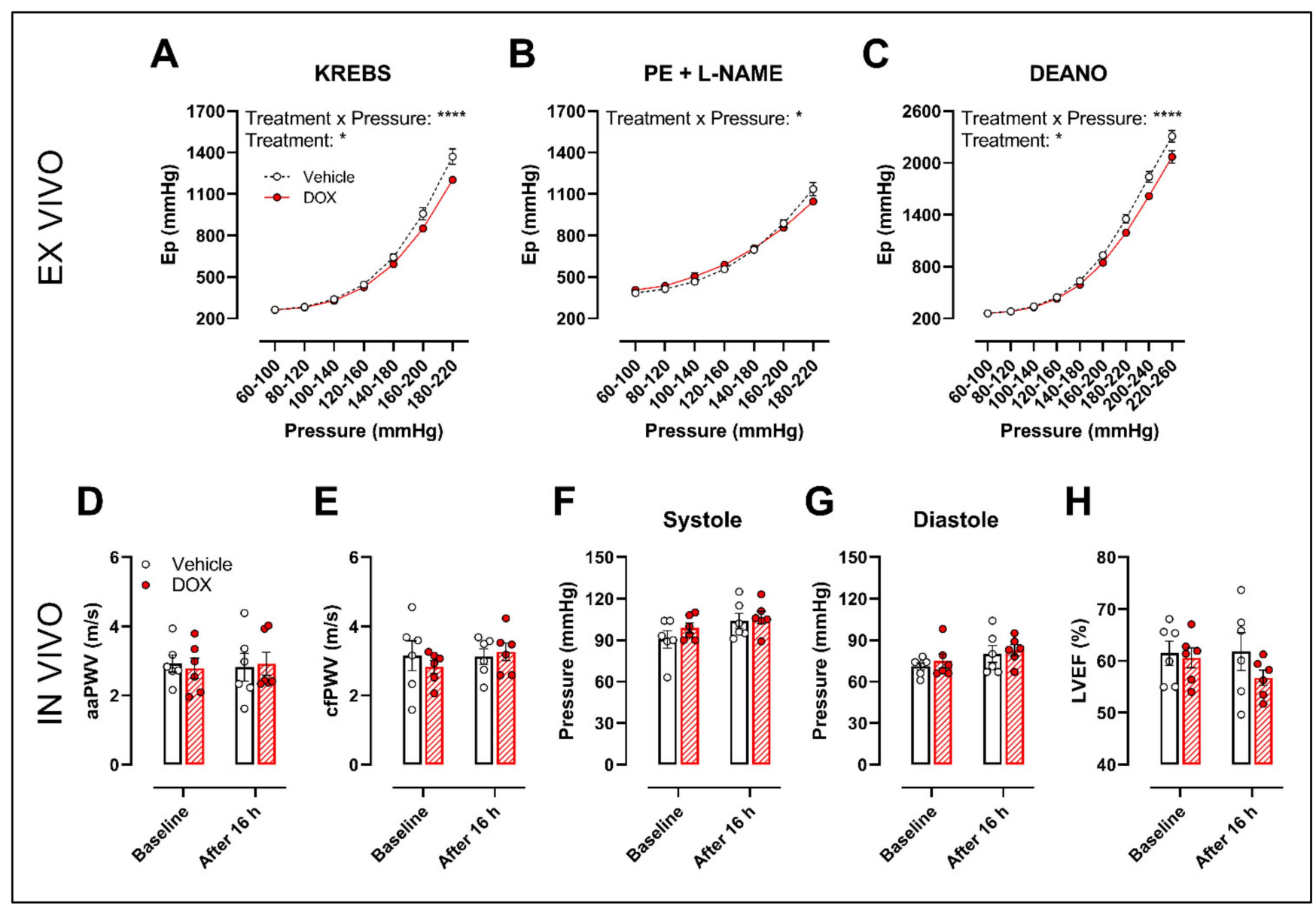

Figure 6. Evaluation of in and ex vivo aortic stiffness, $16 \mathrm{~h}$ after in vivo DOX administration. (A-C) Ex vivo evaluation of arterial stiffness with ROTSAC set-up. (D,E) In vivo evaluation of arterial stiffness with ultrasound imaging (D) and tonometry (E). (F) Systolic blood pressure measurements. (G) Diastolic blood pressure measurements. (H) Evaluation of LVEF with ultrasound imaging. Ep was lower in the DOX-treated group in a pressure-dependent way under Krebs Ringer conditions (A), but the effect was less pronounced in the presence of PE with L-NAME (B). Ep in response to DEANO was lower after DOX treatment (C). aaPWV (D), cfPWV (E), systolic blood pressure (F), diastolic blood pressure (G) and LVEF $(\mathbf{H})$ were not affected after DOX treatment. For $(\mathbf{A}-\mathbf{H})$, repeated measures two-way ANOVA with Šidàk's multiple comparisons test. ${ }^{*}, * * * p<0.05,0.0001 ; n=6$ for each group.

In vivo arterial stiffness was investigated by measuring the abdominal aorta pulse wave velocity (aaPWV) with ultrasound imaging as well as carotid-femoral pulse wave velocity (cfPWV) with tonometry, $16 \mathrm{~h}$ after injecting a single dose of DOX. Blood pressure and left ventricular ejection fraction (LVEF) were measured as well. DOX did not change aaPWV (Figure 6D), cfPWV (Figure 6E), blood pressure (Figure 6F,G) and LVEF (Figure 6H). 


\section{Discussion}

It has been recently recognised that DOX impairs vascular function [11-14,19], yet the exact mechanisms are not fully elucidated yet. While there is consensus about the detrimental effects of DOX on endothelium-dependent vasodilation [19-22], several studies have reported conflicting results on VSMC contraction [23-25]. The present study therefore aimed to investigate VSMC function after a single DOX dose in mice and how it contributes to arterial stiffness.

DOX decreased PE-induced VSMC contraction and impaired ACh-induced endotheliumdependent relaxation in both the in vivo and ex vivo treatment setting. Impaired AChinduced relaxation was in line with previous reports [19-21]. Endothelial cell loss and reduced eNOS-expression contribute to DOX-induced endothelial dysfunction [19-21], which leads to decreased NO bioavailability [28]. This, in turn, results in increased vascular tone and augmented arterial stiffness $[29,30]$. Contradictory, in the present study, we observed a reduction in VSMC contraction following DOX treatment, even after L-NAME addition. L-NAME inhibits eNOS function, thereby excluding the influence of NO in modulating vascular tone. Accordingly, our data suggest that DOX impairs VSMC contraction through a VSMC-specific mechanism.

For the convenience of the reader, Figure 7 illustrates the different mechanisms involved in PE-elicited contraction. Moreover, the different experimental conditions and compounds that were used to elucidate the contributing mechanisms to DOX-induced decrease in VSMC contraction are schematically illustrated in Figure 7 [26].

VSMC sensitivity for NO was not affected by DOX, as evidenced by similar endotheliumindependent relaxation with DEANO. It is thus most likely that the cyclic guanosine monophosphate (cGMP) pathway is not targeted by DOX.

Further experiments demonstrated that DOX did not alter the initial inositol trisphosphate $\left(\mathrm{IP}_{3}\right)$-mediated contraction under $0 \mathrm{mM} \mathrm{Ca}^{2+}$ conditions, suggesting that $\mathrm{DOX}$ does not affect $\mathrm{Ca}^{2+}$ release from the sarcoplasmic reticulum. Moreover, the subsequent decline in force was similar in the vehicle- and DOX-treated groups. This indicates that DOX does not affect $\mathrm{Ca}^{2+}$ uptake and $\mathrm{Ca}^{2}$ efflux, mediated, for example, by the sarco-endoplasmic reticulum and plasmalemma $\mathrm{Ca}^{2+}-$ ATPase pumps, respectively. However, we observed that DOX particularly reduced the tonic contraction phase, which may point to altered $\mathrm{Ca}^{2+}$ influx, either through VGCCs or NSCCs. Relative relaxation of PE-contracted aortic segments with diltiazem, a VGCC-blocker, was not altered after DOX treatment. Under $10-50 \mathrm{mM} \mathrm{K}{ }^{+}$conditions, depolarisation of the membrane potential will promote VGCCmediated contraction. VSMC contraction with different doses of $\mathrm{K}^{+}(10,20,30,40$ and $50 \mathrm{mM}$ ) was similar between the vehicle- and DOX-treated group. Moreover, after preincubation of aortic segments with levcromakalim and diltiazem, tonic VSMC contraction was lower in the DOX-treated group compared with the vehicle-treated group. These findings indicate that VGCCs are not the molecular mechanism explaining the reduced contractions in the presence of DOX. The attenuated VSMC contraction is therefore possibly attributable to DOX-induced alteration of NSCC function. 


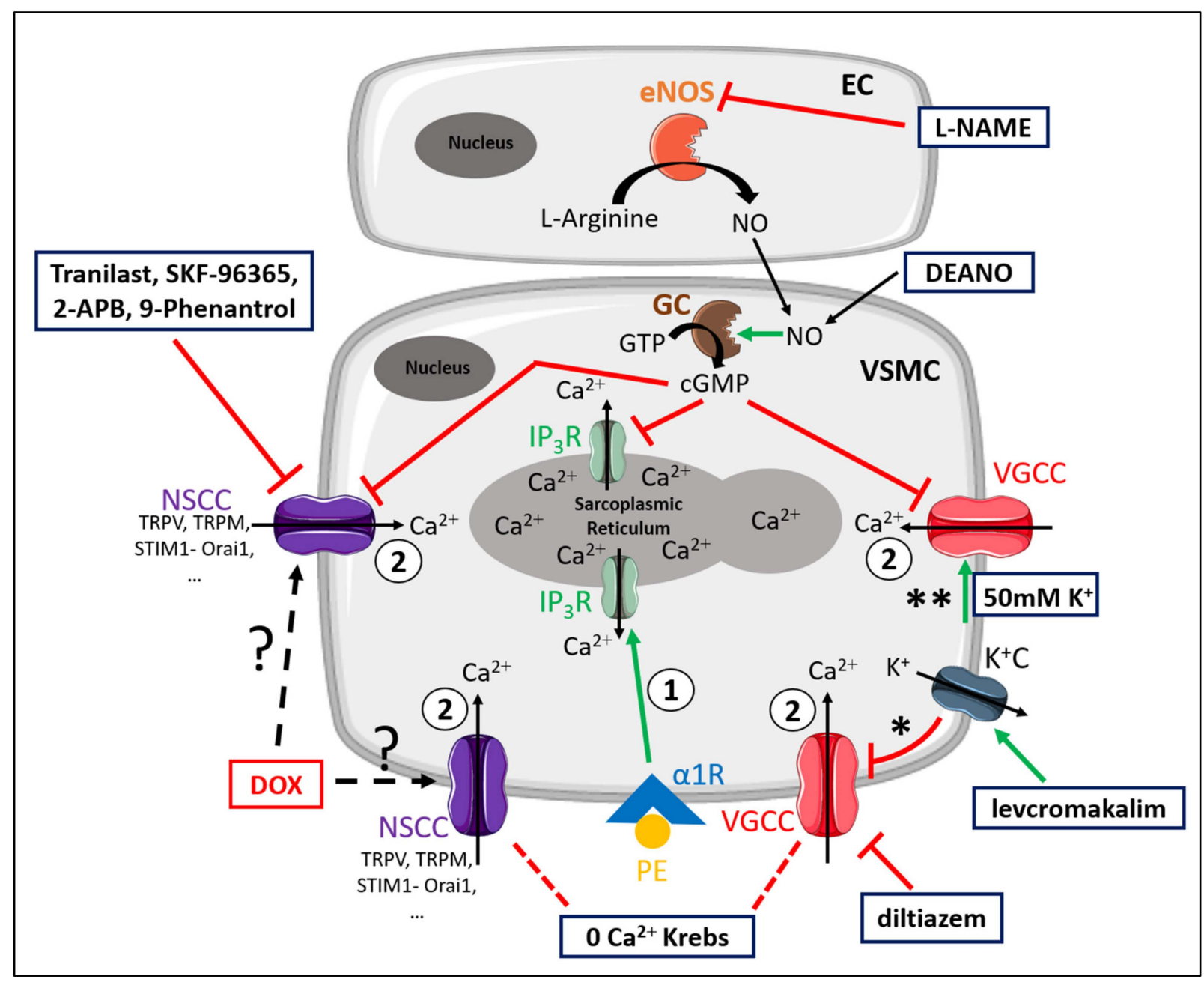

Figure 7. Schematic representation of the PE-elicited VSMC contraction response, including the compounds used to delineate the mechanisms of reduced VSMC contraction after DOX treatment. VSMC contraction through stimulation of $\alpha 1$-adrenergic receptors $(\alpha 1 \mathrm{R})$ with PE is characterised by two components-namely, a fast transient contraction (event 1 ) and a concomitant tonic contraction (event 2) [26]. Event 1: The fast transient contraction is determined by inositol trisphosphate $\left(\mathrm{IP}_{3}\right)$-mediated release of $\mathrm{Ca}^{2+}$ from the sarcoplasmic reticulum through $\mathrm{IP}_{3}$ receptors $\left(\mathrm{IP}_{3} \mathrm{R}\right)$ [26]. Event 2: The concomitant tonic contraction is determined by $\mathrm{Ca}^{2+}$ influx via VGCCs and NSCCs [26]. In both phases, cytoplasmic $\mathrm{Ca}^{2+}$ content increases, thereby forming a $\mathrm{Ca}^{2+}$-calmodulin complex [31], which activates the myosin light chain kinase, promotes the binding of actin to myosin and thus initiates contraction [31]. Production of NO in ECs inhibits $\mathrm{Ca}^{2+}$ release from the sarcoplasmic reticulum and VGCC- and NSCC-mediated $\mathrm{Ca}^{2+}$ influx in a cyclic guanosine monophosphate (cGMP)-dependent way, thereby continuously diminishing contraction [30]. This eNOS-mediated NO production can be inhibited by L-NAME. A $0 \mathrm{mM} \mathrm{Ca}^{2+}$ Krebs environment prevents $\mathrm{Ca}^{2+}$ influx, which results in exclusively $\mathrm{IP}_{3}$-mediated contraction. Diltiazem actively inhibits VGCCs, thereby inhibiting VGCC-mediated $\mathrm{Ca}^{2+}$ influx. Levcromakalim activates ATP-dependent $\mathrm{K}^{+}$channels $\left(\mathrm{K}^{+} \mathrm{C}\right)$, resulting in $\mathrm{K}^{+}$efflux, thereby causing a hyperpolarisation (event ${ }^{*}$ ) of the resting membrane potential and consequently deactivating VGCCs. In the presence of $50 \mathrm{mM} \mathrm{K}{ }^{+}$, depolarisation will occur (event ${ }^{* *}$ ), which will promote VGCC-mediated $\mathrm{Ca}^{2+}$ influx and subsequently leads to VSMC contraction. DEANO acts as an exogenous NO donor and inhibits VGCCs and NSCCs in a manner similar to NO. Members of the diverse family of NSCCs are TRPV, TRPM, STIM1-Orai1, channels, which can be inhibited with tranilast, SKF-96365, 2-APB and 9-phenantrol. DOX may interfere with these channels through an unclear mechanism. Red lines represent inhibition or deactivation, while green lines correspond to activation or stimulation.

Recently, it was found that DOX can inhibit the transient receptor potential vanilloid 2 (TRPV2) channel, a member of the extensive family of NSCCs, in cancer cells by permeating into the channel pore, thereby blocking it $[32,33]$. Transient receptor potential (TRP) channels are involved in tumorigenesis, tumour proliferation and tumour migration [32,34-37]. 
Since the discovery that $\mathrm{Ca}^{2+}$ influx plays a crucial role in cancer development [38], targeting corresponding mediators, such as TRP channels, has proven to be an effective strategy in cancer treatment $[35,37,39]$. Importantly, TRP channels play a pivotal role in VSMC contraction, where they participate in $\mathrm{Ca}^{2+}$ influx and $\mathrm{Ca}^{2+}$ homeostasis [40]. Therefore, it is conceivable that DOX, as a chemotherapeutic drug, also inhibits TRP channels in aortic VSMCs in a manner that is similar to tumour cells, thereby contributing to reduced VSMC contraction and vascular toxicity.

To investigate the possible role of DOX in targeting members of the NSCC family, several NSCC blockers, such as tranilast, SKF-96365, 2-APB and 9-phenantrol were evaluated. We limited our selection of NSCC blockers to inhibitors of TRP channels, which have been proven to be involved in VSMC contraction [40]. One should be cautious in interpreting the data from the experiments evaluating the role of DOX in NSCC function because high molecular structure homology between the different subtypes of TRP channels limits the specificity of corresponding NSCC blockers [40]. Accordingly, we selected two specific TRPV2 inhibitors-namely, tranilast and SKF-96365 (as stated by literature) [41,42]—and the rather general TRP inhibitor 2-APB. Finally, the TRPM4 blocker 9-phenantrol was also used due to a recently identified role of TRPM4 in breast cancer [43].

Surprisingly, DOX treatment resulted in a greater decline in VSMC contraction in the presence of tranilast, SKF-96365, 2-APB and 9-phenantrol, when expressed relative to the preceding contraction magnitude, showing the contribution of TRP channels to PE contractions. This paradoxical finding suggests that TRP channels play a relatively larger role in mediating contraction in DOX-treated aortic segments, and therefore may not be responsible for the decreased VSMC contraction after DOX. Instead, DOX may target other NSCCs that result in attenuated contraction. However, the lack of knowledge regarding the exact role of TRP channels in vascular function, the high diversity of the NSCC family and the interaction between NSCCs mutually [40] constitutes an important limitation in the current study. Further research to elucidate the mechanistic aspects of NSCCs in vascular biology and also how DOX targets these pathways would be interesting, yet such research lies beyond the scope of the present work.

Other agonists, such as endothelin-1, angiotensin II and serotonin were subsequently used to determine whether our observations were specific for PE-involved pathways. Endothelin-1, angiotensin II and serotonin were selected as representative agonists for NSCC-, sarcoplasmic reticulum- and VGCC-mediated contraction, respectively. More specifically, endothelin-1 mainly induces vasoconstriction through VGCC- and NSCCmediated $\mathrm{Ca}^{2+}$ influx, while angiotensin II mediates a phasic contraction through $\mathrm{Ca}^{2+}$ release from intracellular $\mathrm{Ca}^{2+}$ stores, such as the sarcoplasmic reticulum [44]. Serotonin promotes VSMC constriction through $\mathrm{Ca}^{2+}$ release from the sarcoplasmic reticulum in a first transient phase and through primarily VGCC-mediated $\mathrm{Ca}^{2+}$ influx in a second tonic phase [45]. DOX decreased VSMC contraction in response to endothelin-1, but not in the presence of angiotensin II or serotonin. These observations further corroborate that $\mathrm{Ca}^{2+}$ release from intracellular $\mathrm{Ca}^{2+}$ stores as well as $\mathrm{Ca}^{2+}$ influx through VGCCs are not targeted by DOX but that DOX may decrease VSMC contraction through interference with a specific, yet currently unknown, NSCC. Hence, DOX reduces VSMC contraction in a PE receptor-independent way.

Surprisingly, a single dose of DOX decreased ex vivo arterial stiffness at higher pressures, which is in contrast with our previous report where two weeks DOX treatment increased VSMC tone and arterial stiffness [19]. It is important to note that endothelial and VSMC function together actively regulate vascular tone, thereby modulating arterial stiffness $[29,30]$. As such, the occurrence of both impaired endothelium-dependent relaxation and diminished VSMC contraction may have a counteracting effect on arterial stiffness. Another possible explanation for the discrepancies regarding VSMC contraction in the previous [19] and current study lies in the timing for evaluating arterial stiffness. It is conceivable that, in the first acute phase, DOX reduces both VSMC contraction and contributes to endothelial dysfunction, leading to a decrease in arterial stiffness. In a later 
phase, DOX-induced VSMC impairment reverses, most likely due to clearance of DOX from the vascular system over time, while endothelial dysfunction persists. This, in turn, will increase VSMC tone, thereby actively augmenting arterial stiffness.

In contrast with our previously reported work that DOX increased arterial stiffness after two weeks [19], we found no change in in vivo arterial stiffness and blood pressure $16 \mathrm{~h}$ after DOX administration, possibly due to opposing effects of DOX on endothelial and VSMC function. Based on our previous and current data, these findings may have clinical consequences. More specifically, the unchanged and increased arterial stiffness after $16 \mathrm{~h}$ and two weeks of DOX treatment, respectively, may highlight the importance of appropriate timing for evaluating arterial stiffness in DOX-treated patients.

Previous studies have reported decreased VSMC contraction after DOX treatment [23,24]. In these reports, it is hypothesised that DOX-reduced contraction was mediated by diminished $\alpha 1$-adrenergic receptor expression or by ROS-induced VSMC death. While others reported similar results [9,46-49], the data in the current study do not support these proposed mechanisms. In the case of reduced $\alpha 1$-adrenergic receptor expression, the entirety of the PE-contraction response would be affected, including the $\mathrm{IP}_{3}$-mediated contraction, which was not observed. Given the fact that DOX also reduced the endothelin-1-elicited VSMC contraction, it further supports that DOX-decreased contraction occurs independent of $\alpha 1$-adrenergic receptors. Furthermore, depolarisation-induced contraction would be mitigated in the event of VSMC death [50,51], yet contraction under $50 \mathrm{mM} \mathrm{K}^{+}$conditions was not affected, which excludes the occurrence of VSMC death. Hence, our data indicate that DOX decreases VSMC contraction without affecting $\alpha 1$-adrenergic receptor expression or contributing to VSMC death.

The difference in the used dosage of DOX in the present study and the aforementioned literature [23-25] may provide an explanation for the divergent mechanisms. The recommended maximal cumulative DOX dose in patients is $450 \mathrm{mg} / \mathrm{m}^{2}$, which corresponds to $12 \mathrm{mg} / \mathrm{kg}$ (assuming a body surface area of $1.9 \mathrm{~m}^{2}$ and a body weight of 70-75 kg) [52,53]. Additionally, the maximum tolerated dose (MTD) and median lethal dose $\left(\mathrm{LD}_{50}\right)$ of DOX in C57BL6/J mice are both $10 \mathrm{mg} / \mathrm{kg}$ [54]. Previous reports on reduced VSMC contraction following DOX treatment used a single high dose $(>10 \mathrm{mg} / \mathrm{kg})$, which could induce VSMC death $[21,23,24]$. In the current work, however, a lower DOX dose $(4 \mathrm{mg} / \mathrm{kg}$ ) was used for optimal comparison with previous work, which may affect VSMC function differently.

As a secondary goal, we aimed to develop an ex vivo experimental platform for mechanistic studies and for drug screening. In this experimental setting, a DOX dose of $1 \mu \mathrm{M}$ was used, which is within therapeutic range, since plasma concentrations of DOX have been reported to fluctuate between 0.3 and $1 \mu \mathrm{M}$ in patients $[48,55]$. Since the observed changes in vascular reactivity in response to DOX were similar in vivo and ex vivo, the platform holds potential for future drug screening.

In conclusion, the present study reports decreased VSMC contraction with coinciding endothelial dysfunction after DOX treatment $(4 \mathrm{mg} / \mathrm{kg})$. The decrease in contraction does not relate to alterations in intracellular $\mathrm{Ca}^{2+}$ release or $\mathrm{Ca}^{2+}$ influx through VGCCs, but points towards a modulating role for DOX in NSCC function. Experiments with TRP blocking agents failed to pinpoint the exact mechanism causing reduced VSMC contractions, suggesting that DOX may target other NSCCs instead. Importantly, the observation of unchanged in vivo arterial stiffness or blood pressure, possibly due to counteracting effects of DOX on EC and VSMC function, may highlight the importance of timing for evaluation of DOX-induced arterial stiffness in patients.

\section{Materials and Methods}

\subsection{Animals and Ethical Approval}

Male C57BL/6J mice (Charles River, Ecully, France) with an age of 10 to 12 weeks and a body weight between 26 and $30 \mathrm{~g}$ were used for all experiments. Mice were housed in the animal facility of the University of Antwerp in standard cages with 12-12 h light-dark cycles with access to regular chow and water ad libitum. To avoid the influence of female 
hormone confounding factors, male mice were chosen. All experiments in this work were approved by the Ethical Committee of the University of Antwerp (dossier 2019-34) and conformed with the ARRIVE guidelines, with the Guide for the Care and Use of Laboratory Animals published by the US National Institutes of Health (NIH Publication no. 85-23, revised 1996) and with the Belgian Royal Decree of 2013.

\subsection{DOX Treatment and Experimental Workflow}

The current study composed two distinct experimental parts—namely, a part where DOX was administered to mice (in vivo DOX treatment), and a second part where aortic segments were first isolated from mice and subsequently either treated with vehicle or DOX (ex vivo DOX treatment).

For in vivo DOX treatment: $C 57 B L / 6 J$ mice received a single intraperitoneal injection of $4 \mathrm{mg} / \mathrm{kg}$ DOX (Adriamycin ${ }^{\circledR}(2 \mathrm{mg} / \mathrm{mL}$ ), Pfizer, Puurs, Belgium) or $10 \mathrm{~mL} / \mathrm{kg}$ of a $0.9 \% \mathrm{NaCl}$ solution (B. Braun, Machelen, Belgium) as vehicle. DOX was diluted in a $0.9 \%$ $\mathrm{NaCl}$ solution on the day of injection. Based on other studies that investigated acute DOX effects $[21,23,24,56]$, mice were sacrificed $16 \mathrm{~h}$ later for vascular reactivity evaluation in organ baths with isometric transducer. To this end, mice were intraperitoneally injected with sodium pentobarbital (100 mg/kg; Sanofi, Machelen, Belgium), followed by perforation of the diaphragm (when under deep anaesthesia). The thoracic aorta was carefully dissected and cut into six segments of $2 \mathrm{~mm}$ length (i.e., TA0 to TA5), with the crossing of the diaphragm as the reference point for the sixth segment (TA5). Next, TA3, TA4 and TA5 segments were mounted between two hooks of an organ bath set-up $(10 \mathrm{~mL})$ filled with Krebs Ringer solution $\left(37^{\circ} \mathrm{C}, 95 \% \mathrm{O} 2 / 5 \% \mathrm{CO} 2, \mathrm{pH} 7.4\right)$ for vascular reactivity and arterial stiffness evaluation. The Krebs Ringer solution contained (in mmol/L) $\mathrm{NaCl} 118, \mathrm{KCl} 4.7$, $\mathrm{CaCl}_{2}$ 2.5, $\mathrm{KH}_{2} \mathrm{PO}_{4} 1.2, \mathrm{MgSO}_{4} 1.2, \mathrm{NaHCO}_{3}$ 25, CaEDTA 0.025 and glucose 11.1.

For ex vivo DOX treatment: Healthy wild-type C57BL/6J mice were first sacrificed and the aorta was subsequently isolated, as described above. Following dissection, aortic segments were immediately transferred to Dulbecco's modified Eagle medium (DMEM) medium (Thermo Fisher Scientific, Geel, Belgium) supplemented with 1\% penicillin/streptomycin (Thermo Fisher Scientific, Geel, Belgium). Aortic segments were randomly divided and received either phosphate-buffered saline solution (PBS) as vehicle (1:100) or DOX $(1 \mu \mathrm{M})$ for $16 \mathrm{~h}$. DOX was diluted in PBS on the day of the experiment. After $16 \mathrm{~h}$, aortic segments were mounted between two hooks of an organ bath set-up $\left(10 \mathrm{~mL}\right.$ ) filled with Krebs Ringer solution $\left(37^{\circ} \mathrm{C}, 95 \% \mathrm{O}_{2} / 5 \% \mathrm{CO}_{2}, \mathrm{pH} 7.4\right)$ for vascular reactivity evaluation.

\subsection{High-Frequency Ultrasound Imaging}

Ultrasound imaging was performed in anaesthetised mice under $1.5-2.5 \%(v / v)$ isoflurane (Forene; Abbvie, Wavre, Belgium) using a high-frequency ultrasound system (Vevo2100, VisualSonics, Toronto, Canada). Images were only acquired when heart rate and body temperature met the inclusion criteria, i.e., $550 \pm 50$ beats $/ \mathrm{min}$ and $37 \pm 1{ }^{\circ} \mathrm{C}$, respectively. M-mode images were obtained for determination of cardiac parameters using a $24 \mathrm{MHz}$ transducer. LVEF was subsequently calculated using measurements of three consecutive M-mode cycles with Vevo LAB Software (Version 3.2.0, VisualSonics, Toronto, Canada). In the same session, abdominal aorta PWV (aaPWV) was determined according to the method developed by Di Lascio et al. with a $24 \mathrm{MHz}$ transducer [57]. Briefly, pulse wave Doppler tracing was used to measure aortic flow velocity $(\mathrm{V})$. Immediately thereafter, aortic diameter (D) was measured on 700 frames-per-second B-mode images of the abdominal aorta in EKV imaging mode. The $\ln (\mathrm{D})-\mathrm{V}$ loop method was then applied to calculate aaPWV, using MATLAB v2014 software (MathWorks, Eindhoven, the Netherlands).

\subsection{Applanation Tonometry}

cfPWV was determined in anaesthetised mice under 1.5-2.5\% $(v / v)$ isoflurane (Forene; Abbvie, Wavre, Belgium), as previously described by our research group [58]. In brief, 
two pulse tonometers (SPT-301, Millar Instruments, Wokingham, United Kingdom) were applied on the skin using a micromanipulator. Carotid-femoral transit time $(\Delta t)$ was determined using the time difference between the foot of carotid and femoral artery pulses (foot-to-foot method). The foot of the pressure wave was defined as the second derivative maximum. Twenty consecutive pulses with sufficient amplitude and a reproducible waveform were analysed; pulses that interfered with respiratory movement peaks were excluded.

\subsection{Blood Pressure Evaluation}

Systolic and diastolic blood pressure were determined non-invasively in restrained, awake mice using a tail-cuff system with programmed electrosphygmomanometer (Coda, Kent Scientific Corporation, Torrington, United States of America). To reduce stress and variability during the procedure, animals were trained for two days prior to the actual measurements.

\subsection{Evaluation of Vascular Reactivity}

For clarity, the standard experimental protocol for the in vivo and ex vivo DOX treatment experiments is illustrated in Supplementary Figures S1 and S2, respectively. Aortic segments were mounted at a preload of $20 \mathrm{mN}$. Since we have previously shown that basal NO declines over time [27], the experimental protocol for in vivo DOX-treated aortic segments was started exactly 70 min after puncture of the diaphragm to minimise timedependent biases. Ex vivo DOX-treated aortic segments were also mounted at a preload of $20 \mathrm{mN}$, and the experimental protocol was started $20 \mathrm{~min}$ thereafter to allow optimal stabilisation. VSMC contraction was evaluated by adding cumulative concentrations of PE (3 nM-3 $\mu \mathrm{M})$, an $\alpha 1$-adrenergic receptor agonist. Next, endothelium-dependent relaxation was investigated by addition of cumulative concentrations of ACh ( $3 \mathrm{nM}-10 \mu \mathrm{M})$, a muscarinic receptor agonist.

The PE-elicited contraction response was further investigated by incubating the aortic segments in the organ bath with a single PE-dose of $2 \mu \mathrm{M}$ for $15 \mathrm{~min}$. Once the contraction was stable after $15 \mathrm{~min}$, L-NAME $(300 \mu \mathrm{M})$ was subsequently added, further increasing contraction (PE + L-NAME contraction). L-NAME is an eNOS blocker, which inhibits NO production and allows evaluation of the involvement of the endothelial cell layer in regulating VSMC contraction and tone. After $20 \mathrm{~min}$, cumulative concentrations of the exogenous NO-donor DEANO $(0.3 \mathrm{nM}-10 \mu \mathrm{M})$ were added to the organ bath to evaluate endothelium-independent relaxation of VSMCs through the CGMP-mediated pathway.

The contraction via $\mathrm{IP}_{3}$-mediated $\mathrm{Ca}^{2+}$ release from the sarcoplasmic reticulum was investigated by incubating aortic segments with $\mathrm{Ca}^{2+}$-free Krebs Ringer solution $(0 \mathrm{mM}$ $\left.\mathrm{Ca}^{2+}\right)$ for three minutes, followed by addition of PE $(2 \mu \mathrm{M})$ for three minutes. The $0 \mathrm{mM}$ $\mathrm{Ca}^{2+}$ Krebs Ringer solution contained (in mmol/L): $\mathrm{NaCl} 118, \mathrm{KCl} 4.7, \mathrm{CaCl}_{2} 0, \mathrm{KH}_{2} \mathrm{PO}_{4}$ $1.2, \mathrm{MgSO}_{4}$ 1.2, $\mathrm{NaHCO}_{3}$ 25, CaEDTA 0.025, EGTA 1.0 and glucose 11.1. An extracellular $0 \mathrm{mM} \mathrm{Ca}^{2+}$ environment will prevent $\mathrm{Ca}^{2+}$ influx during PE contraction, which will shift contraction to solely $\mathrm{Ca}^{2+}$ release from the sarcoplasmic reticulum [26]. Next, $\mathrm{CaCl}_{2}$ (3.5 mM) was added to restore $\mathrm{Ca}^{2+}$-containing Krebs, which resulted in contraction in a similar way as the PE-elicited contraction response [26]. Finally, the involvement of VGCCs was determined by adding a single, high concentration (35 $\mu \mathrm{M})$ of diltiazem, a voltage-gated $\mathrm{Ca}^{2+}$-channel blocker. This resulted in relaxation, which offered an estimate of the amount of contraction that was attributable to VGCCs.

To determine the role of VSMC membrane potential in modulating contraction, a doseresponse of $\mathrm{K}^{+}(10 \mathrm{mM}, 20 \mathrm{mM}, 30 \mathrm{mM}, 40 \mathrm{mM}$ and $50 \mathrm{mM})$ was performed in the organ bath. A high dose of $\mathrm{K}^{+}$causes depolarisation of the membrane potential, thereby activating VGCC-mediated $\mathrm{Ca}^{2+}$ influx, which eventually results in contraction [26,59]. Finally, the VGCC blockers levcromakalim $(1 \mu \mathrm{M})$ and diltiazem $(35 \mu \mathrm{M})$ and the NSCC blockers tranilast $(100 \mu \mathrm{M})$, SKF-96365 $(10 \mu \mathrm{M}), 2-\mathrm{APB}(20 \mu \mathrm{M})$ and 9-phenantrol $(1 \mu \mathrm{M})$ were used to delineate the involvement of NSCCs in the PE-elicited contraction response. Levcromakalim hyperpolarises the VSMC membrane potential, thereby deactivating VGCCs, 
which will consequently inhibit $\mathrm{Ca}^{2+}$ influx via these channels $[26,60]$. These experiments were performed in the presence of L-NAME to exclude the influence of NO on VGCCs and NSCCs. Prior to the addition of a NSCC blocker, PE-contraction was elicited in the presence of diltiazem, thereby promoting $\mathrm{Ca}^{2+}$ influx through NSCCs. The protocol for investigation of NSCCs in modulating contraction is illustrated in Supplementary Figure S3.

\subsection{Evaluation of Arterial Stiffness in ROTSAC}

Ex vivo assessment of arterial stiffness was performed using the ROTSAC, as previously described $[19,61]$. In brief, segments (TA3) were continuously stretched between alternating preloads corresponding to "systolic" and "diastolic" transmural pressures. Calibration of the set-up allows calculation in real-time of the "systolic" and "diastolic" pressure and the Peterson's modulus (Ep), a measure of arterial stiffness, based on LaPlace's equation. Ep was calculated as follows: $\mathrm{Ep}=\mathrm{D}_{0} * \Delta \mathrm{P} / \Delta \mathrm{D}$, with $\Delta \mathrm{P}=$ difference in pressure (kept constant at $40 \mathrm{mmHg}$ ), $\mathrm{D}_{0}=$ "diastolic" diameter and $\Delta \mathrm{D}=$ the change in diameter between "diastolic" and "systolic" pressure. The ROTSAC protocol included the evaluation of arterial stiffness (Ep) at different pressures (i.e., $60-100$ until $220-260 \mathrm{mmHg}$ with $20 \mathrm{mmHg}$ intervals). The contribution of VSMC tonus was investigated by adding a high concentration $(2 \mu \mathrm{M})$ of PE combined with L-NAME $(300 \mu \mathrm{M})$.

\subsection{Chemical Compounds}

DOX (Adriamycin ${ }^{\circledR}, 2 \mathrm{mg} / \mathrm{mL}$ ) was purchased from Pfizer (Puurs, Belgium). PE, L-NAME, ACh, DEANO, diltiazem, tranilast, SKF-96365, 9-phenantrol, serotonin hydrochloride and angiotensin II (human) were obtained from Sigma-Aldrich (Overijse, Belgium). Levcromakalim and 2-APB were purchased from TOCRIS (Bristol, United Kingdom). Finally, endothelin-1 was supplied by Alexis ${ }^{\circledR}$ Biochemicals (Enzo Life Sciences, Zandhoven, Belgium).

\subsection{Statistical Analysis}

All results are expressed as the mean \pm standard error of the mean (SEM). Statistical analyses were performed using GraphPad Software (Prism 9-Version 9.2.0; Graphpad, California, United States of America). A $p$-value $<0.05$ was considered to be statistically significant.

Supplementary Materials: The following are available online at https:/ / www.mdpi.com/article/10 $.3390 /$ ijms222312812/s1.

Author Contributions: Conceptualization: M.B., E.M.V.C. and P.-J.D.F.G.; methodology: M.B., D.N.K. and C.D.W.; investigation and formal analysis: M.B., D.N.K., C.D.W., C.H.G.N., B.V.A., O.R.D., B.F., T.J.S. and P.-J.D.F.G.; writing — original draft preparation: M.B., E.M.V.C. and P.-J.D.F.G.; writingreview and editing: M.B., D.N.K., C.D.W., K.F., C.H.G.N., B.V.A., W.M., G.R.Y.D.M., E.M.V.C. and P.J.D.F.G.; supervision: E.M.V.C. and P.-J.D.F.G.; funding acquisition: G.R.Y.D.M., W.M., E.M.V.C. and P.-J.D.F.G. All authors have read and agreed to the published version of the manuscript.

Funding: M.B., K.F. and C.N. are predoctoral fellows of the Fund for Scientific Research (FWO) Flanders (grant number: 1S33720N, 11C6321N and 1S24720N, respectively). E.V.C. is holder of a senior clinical investigator grant from FWO Flanders (grant number: 1804320N). Furthermore, the research was supported by a DOCPRO4 grant of the Research Council of the University of Antwerp (ID: 39984) and the INSPIRE project, which has received funding from the European Union's Horizon 2020 Research and Innovation Program (H2020-MSCA-ITN program, Grant Agreement: No858070).

Institutional Review Board Statement: The study was approved by the Ethical Committee for Animal Testing of the University of Antwerp (dossier 2019-34) on 23 October 2019.

Informed Consent Statement: Not applicable.

Data Availability Statement: Not applicable. 
Conflicts of Interest: The authors declare no conflict of interest. The funders had no role in the design of the study; in the collection, analyses, or interpretation of data; in the writing of the manuscript; or in the decision to publish the results.

\section{References}

1. Thorn, C.F.; Oshiro, C.; Marsh, S.; Hernandez-Boussard, T.; McLeod, H.; Klein, T.E.; Altman, R.B. Doxorubicin pathways: Pharmacodynamics and adverse effects. Pharm. Genom. 2011, 21, 440-446. [CrossRef]

2. Mitry, M.A.; Edwards, J.G. Doxorubicin induced heart failure: Phenotype and molecular mechanisms. Int. J. Cardiol. Heart Vasc. 2016, 10, 17-24. [CrossRef] [PubMed]

3. Bryant, J.; Picot, J.; Baxter, L.; Levitt, G.; Sullivan, I.; Clegg, A. Clinical and cost-effectiveness of cardioprotection against the toxic effects of anthracyclines given to children with cancer: A systematic review. Br. J. Cancer 2007, 96, 226-230. [CrossRef]

4. Kremer, L.C.; van Dalen, E.C.; Offringa, M.; Voute, P.A. Frequency and risk factors of anthracycline-induced clinical heart failure in children: A systematic review. Ann. Oncol. 2002, 13, 503-512. [CrossRef] [PubMed]

5. Schlitt, A.; Jordan, K.; Vordermark, D.; Schwamborn, J.; Langer, T.; Thomssen, C. Cardiotoxicity and oncological treatments. Dtsch. Arztebl. Int. 2014, 111, 161-168. [CrossRef]

6. Floyd, J.D.; Nguyen, D.T.; Lobins, R.L.; Bashir, Q.; Doll, D.C.; Perry, M.C. Cardiotoxicity of cancer therapy. J. Clin. Oncol. 2005, 23, 7685-7696. [CrossRef] [PubMed]

7. Renu, K.; Abilash, V.G.; Tirupathi Pichiah, P.B.; Arunachalam, S. Molecular mechanism of doxorubicin-induced cardiomyopathyAn update. Eur. J. Pharmacol. 2018, 818, 241-253. [CrossRef]

8. Armstrong, G.T.; Oeffinger, K.C.; Chen, Y.; Kawashima, T.; Yasui, Y.; Leisenring, W.; Stovall, M.; Chow, E.J.; Sklar, C.A.; Mulrooney, D.A.; et al. Modifiable risk factors and major cardiac events among adult survivors of childhood cancer. J. Clin. Oncol. 2013, 31, 3673-3680. [CrossRef]

9. Luu, A.Z.; Chowdhury, B.; Al-Omran, M.; Teoh, H.; Hess, D.A.; Verma, S. Role of Endothelium in Doxorubicin-Induced Cardiomyopathy. JACC Basic Transl. Sci. 2018, 3, 861-870. [CrossRef]

10. Bar-Joseph, H.; Ben-Aharon, I.; Tzabari, M.; Tsarfaty, G.; Stemmer, S.M.; Shalgi, R. In vivo bioimaging as a novel strategy to detect doxorubicin-induced damage to gonadal blood vessels. PLoS ONE 2011, 6, e23492. [CrossRef] [PubMed]

11. Parr, S.K.; Liang, J.; Schadler, K.L.; Gilchrist, S.C.; Steele, C.C.; Ade, C.J. Anticancer Therapy-Related Increases in Arterial Stiffness: A Systematic Review and Meta-Analysis. J. Am. Heart Assoc. 2020, 9, e015598. [CrossRef]

12. Novo, G.; Di Lisi, D.; Manganaro, R.; Manno, G.; Lazzara, S.; Immordino, F.A.; Madaudo, C.; Carerj, S.; Russo, A.; Incorvaia, L.; et al. Arterial Stiffness: Effects of Anticancer Drugs Used for Breast Cancer Women. Front. Physiol. 2021, $12,661464$. [CrossRef] [PubMed]

13. Yersal, O.; Eryilmaz, U.; Akdam, H.; Meydan, N.; Barutca, S. Arterial Stiffness in Breast Cancer Patients Treated with Anthracycline and Trastuzumab-Based Regimens. Cardiol. Res. Pract. 2018, 2018, 5352914. [CrossRef]

14. Chaosuwannakit, N.; D’Agostino, R., Jr.; Hamilton, C.A.; Lane, K.S.; Ntim, W.O.; Lawrence, J.; Melin, S.A.; Ellis, L.R.; Torti, F.M.; Little, W.C.; et al. Aortic stiffness increases upon receipt of anthracycline chemotherapy. J. Clin. Oncol. 2010, 28, 166-172. [CrossRef] [PubMed]

15. Chae, C.U.; Pfeffer, M.A.; Glynn, R.J.; Mitchell, G.F.; Taylor, J.O.; Hennekens, C.H. Increased pulse pressure and risk of heart failure in the elderly. JAMA 1999, 281, 634-639. [CrossRef]

16. Sutton-Tyrrell, K.; Najjar, S.S.; Boudreau, R.M.; Venkitachalam, L.; Kupelian, V.; Simonsick, E.M.; Havlik, R.; Lakatta, E.G.; Spurgeon, H.; Kritchevsky, S.; et al. Elevated aortic pulse wave velocity, a marker of arterial stiffness, predicts cardiovascular events in well-functioning older adults. Circulation 2005, 111, 3384-3390. [CrossRef]

17. Mitchell, G.F.; Vasan, R.S.; Keyes, M.J.; Parise, H.; Wang, T.J.; Larson, M.G.; D’Agostino, R.B., Sr.; Kannel, W.B.; Levy, D.; Benjamin, E.J. Pulse pressure and risk of new-onset atrial fibrillation. JAMA 2007, 297, 709-715. [CrossRef]

18. Nagy, L.; Szabo, F.; Ivanyi, J.; Nemeth, L.; Kovacs, G.L.; Palatka, J.; Tarjan, J.; Toth, K.; Roth, E. A method for detection of doxorubicin-induced cardiotoxicity: Flow-mediated vasodilation of the brachial artery. Exp. Clin. Cardiol. 2001, 6, 87-92.

19. Bosman, M.; Favere, K.; Neutel, C.H.G.; Jacobs, G.; De Meyer, G.R.Y.; Martinet, W.; Van Craenenbroeck, E.M.; Guns, P.D.F. Doxorubicin induces arterial stiffness: A comprehensive in vivo and ex vivo evaluation of vascular toxicity in mice. Toxicol. Lett. 2021, 346, 23-33. [CrossRef]

20. He, H.; Wang, L.; Qiao, Y.; Zhou, Q.; Li, H.; Chen, S.; Yin, D.; Huang, Q.; He, M. Doxorubicin Induces Endotheliotoxicity and Mitochondrial Dysfunction via ROS/eNOS/NO Pathway. Front. Pharmacol. 2019, 10, 1531. [CrossRef] [PubMed]

21. Duquaine, D.; Hirsch, G.A.; Chakrabarti, A.; Han, Z.; Kehrer, C.; Brook, R.; Joseph, J.; Schott, A.; Kalyanaraman, B.; Vasquez-Vivar, J.; et al. Rapid-onset endothelial dysfunction with adriamycin: Evidence for a dysfunctional nitric oxide synthase. Vasc. Med. 2003, 8, 101-107. [CrossRef] [PubMed]

22. Kalivendi, S.V.; Kotamraju, S.; Zhao, H.; Joseph, J.; Kalyanaraman, B. Doxorubicin-induced apoptosis is associated with increased transcription of endothelial nitric-oxide synthase. Effect of antiapoptotic antioxidants and calcium. J. Biol. Chem. 2001, 276, 47266-47276. [CrossRef] [PubMed]

23. Gibson, N.M.; Greufe, S.E.; Hydock, D.S.; Hayward, R. Doxorubicin-induced vascular dysfunction and its attenuation by exercise preconditioning. J. Cardiovasc. Pharmacol. 2013, 62, 355-360. [CrossRef] [PubMed] 
24. Olukman, M.; Can, C.; Erol, A.; Oktem, G.; Oral, O.; Cinar, M.G. Reversal of doxorubicin-induced vascular dysfunction by resveratrol in rat thoracic aorta: Is there a possible role of nitric oxide synthase inhibition? Anadolu Kardiyol. Derg. 2009, 9, 260-266. [PubMed]

25. Shen, B.; Ye, C.L.; Ye, K.H.; Zhuang, L.; Jiang, J.H. Doxorubicin-induced vasomotion and [Ca(2+)](i) elevation in vascular smooth muscle cells from C57BL/6 mice. Acta Pharmacol. Sin. 2009, 30, 1488-1495. [CrossRef]

26. Fransen, P.; Van Hove, C.E.; Leloup, A.J.; Martinet, W.; De Meyer, G.R.; Lemmens, K.; Bult, H.; Schrijvers, D.M. Dissecting out the complex $\mathrm{Ca}^{2+}$-mediated phenylephrine-induced contractions of mouse aortic segments. PLoS ONE 2015, 10, e0121634. [CrossRef]

27. van Langen, J.; Fransen, P.; Van Hove, C.E.; Schrijvers, D.M.; Martinet, W.; De Meyer, G.R.; Bult, H. Selective loss of basal but not receptor-stimulated relaxation by endothelial nitric oxide synthase after isolation of the mouse aorta. Eur. J. Pharmacol. 2012, 696, 111-119. [CrossRef]

28. Fitch, R.M.; Vergona, R.; Sullivan, M.E.; Wang, Y.X. Nitric oxide synthase inhibition increases aortic stiffness measured by pulse wave velocity in rats. Cardiovasc. Res. 2001, 51, 351-358. [CrossRef]

29. Leloup, A.J.A.; Van Hove, C.E.; De Moudt, S.; De Keulenaer, G.W.; Fransen, P. Ex vivo aortic stiffness in mice with different eNOS activity. Am. J. Physiol. Heart Circ. Physiol. 2020, 318, H1233-H1244. [CrossRef]

30. Leloup, A.J.A.; Van Hove, C.E.; De Moudt, S.; De Meyer, G.R.Y.; De Keulenaer, G.W.; Fransen, P. Vascular smooth muscle cell contraction and relaxation in the isolated aorta: A critical regulator of large artery compliance. Physiol. Rep. 2019, 7, e13934. [CrossRef]

31. Brozovich, F.V.; Nicholson, C.J.; Degen, C.V.; Gao, Y.Z.; Aggarwal, M.; Morgan, K.G. Mechanisms of Vascular Smooth Muscle Contraction and the Basis for Pharmacologic Treatment of Smooth Muscle Disorders. Pharmacol. Rev. 2016, 68, 476-532. [CrossRef]

32. Neumann-Raizel, H.; Shilo, A.; Lev, S.; Mogilevsky, M.; Katz, B.; Shneor, D.; Shaul, Y.D.; Leffler, A.; Gabizon, A.; Karni, R.; et al. 2-APB and CBD-Mediated Targeting of Charged Cytotoxic Compounds Into Tumor Cells Suggests the Involvement of TRPV2 Channels. Front. Pharmacol. 2019, 10, 1198. [CrossRef]

33. Ghosh, D.; Syed, A.U.; Prada, M.P.; Nystoriak, M.A.; Santana, L.F.; Nieves-Cintron, M.; Navedo, M.F. Calcium Channels in Vascular Smooth Muscle. Adv. Pharmacol. 2017, 78, 49-87. [CrossRef]

34. Prevarskaya, N.; Zhang, L.; Barritt, G. TRP channels in cancer. Biochim. Biophys. Acta 2007, 1772, 937-946. [CrossRef]

35. Santoni, G.; Farfariello, V. TRP channels and cancer: New targets for diagnosis and chemotherapy. Endocr. Metab. Immune Disord. Drug Targets 2011, 11, 54-67. [CrossRef] [PubMed]

36. Fiorio Pla, A.; Gkika, D. Emerging role of TRP channels in cell migration: From tumor vascularization to metastasis. Front. Physiol. 2013, 4, 311. [CrossRef] [PubMed]

37. Chen, J.; Luan, Y.; Yu, R.; Zhang, Z.; Zhang, J.; Wang, W. Transient receptor potential (TRP) channels, promising potential diagnostic and therapeutic tools for cancer. Biosci. Trends 2014, 8, 1-10. [CrossRef] [PubMed]

38. Azimi, I.; Roberts-Thomson, S.J.; Monteith, G.R. Calcium influx pathways in breast cancer: Opportunities for pharmacological intervention. Br. J. Pharmacol. 2014, 171, 945-960. [CrossRef] [PubMed]

39. Kosar, P.A.; Naziroglu, M.; Ovey, I.S.; Cig, B. Synergic Effects of Doxorubicin and Melatonin on Apoptosis and Mitochondrial Oxidative Stress in MCF-7 Breast Cancer Cells: Involvement of TRPV1 Channels. J. Membr. Biol. 2016, 249, 129-140. [CrossRef]

40. Earley, S.; Brayden, J.E. Transient receptor potential channels in the vasculature. Physiol. Rev. 2015, 95, 645-690. [CrossRef]

41. Iwata, Y.; Katayama, Y.; Okuno, Y.; Wakabayashi, S. Novel inhibitor candidates of TRPV2 prevent damage of dystrophic myocytes and ameliorate against dilated cardiomyopathy in a hamster model. Oncotarget 2018, 9, 14042-14057. [CrossRef]

42. Iwata, Y.; Matsumura, T. Blockade of TRPV2 is a Novel Therapy for Cardiomyopathy in Muscular Dystrophy. Int. J. Mol. Sci. 2019, 20, 3844. [CrossRef] [PubMed]

43. Verigos, J.; Kordias, D.; Papadaki, S.; Magklara, A. Transcriptional Profiling of Tumorspheres Reveals TRPM4 as a Novel Stemness Regulator in Breast Cancer. Biomedicines 2021, 9, 1368. [CrossRef]

44. Wynne, B.M.; Chiao, C.W.; Webb, R.C. Vascular Smooth Muscle Cell Signaling Mechanisms for Contraction to Angiotensin II and Endothelin-1. J. Am. Soc. Hypertens. 2009, 3, 84-95. [CrossRef]

45. Bhaskaran, S.; Zaluski, J.; Banes-Berceli, A. Molecular interactions of serotonin (5-HT) and endothelin-1 in vascular smooth muscle cells: In vitro and ex vivo analyses. Am. J. Physiol. Cell Physiol. 2014, 306, C143-C151. [CrossRef]

46. Kotamraju, S.; Konorev, E.A.; Joseph, J.; Kalyanaraman, B. Doxorubicin-induced apoptosis in endothelial cells and cardiomyocytes is ameliorated by nitrone spin traps and ebselen. Role of reactive oxygen and nitrogen species. J. Biol. Chem. 2000, 275, 33585-33592. [CrossRef] [PubMed]

47. Kannan, K.; Jain, S.K. Oxidative stress and apoptosis. Pathophysiology 2000, 7, 153-163. [CrossRef]

48. Murata, T.; Yamawaki, H.; Yoshimoto, R.; Hori, M.; Sato, K.; Ozaki, H.; Karaki, H. Chronic effect of doxorubicin on vascular endothelium assessed by organ culture study. Life Sci. 2001, 69, 2685-2695. [CrossRef]

49. Li, J.; Li, P.F.; Dietz, R.; von Harsdorf, R. Intracellular superoxide induces apoptosis in VSMCs: Role of mitochondrial membrane potential, cytochrome $C$ and caspases. Apoptosis 2002, 7, 511-517. [CrossRef]

50. Numaga-Tomita, T.; Shimauchi, T.; Oda, S.; Tanaka, T.; Nishiyama, K.; Nishimura, A.; Birnbaumer, L.; Mori, Y.; Nishida, M. TRPC6 regulates phenotypic switching of vascular smooth muscle cells through plasma membrane potential-dependent coupling with PTEN. FASEB J. 2019, 33, 9785-9796. [CrossRef] 
51. Petsophonsakul, P.; Furmanik, M.; Forsythe, R.; Dweck, M.; Schurink, G.W.; Natour, E.; Reutelingsperger, C.; Jacobs, M.; Mees, B.; Schurgers, L. Role of Vascular Smooth Muscle Cell Phenotypic Switching and Calcification in Aortic Aneurysm Formation. Arterioscler. Thromb. Vasc. Biol. 2019, 39, 1351-1368. [CrossRef] [PubMed]

52. Zamorano, J.L.; Lancellotti, P.; Rodriguez Munoz, D.; Aboyans, V.; Asteggiano, R.; Galderisi, M.; Habib, G.; Lenihan, D.J.; Lip, G.Y.H.; Lyon, A.R.; et al. ESC Position Paper on cancer treatments and cardiovascular toxicity developed under the auspices of the ESC Committee for Practice Guidelines: The Task Force for cancer treatments and cardiovascular toxicity of the European Society of Cardiology (ESC). Eur. Heart J. 2016, 37, 2768-2801. [CrossRef]

53. Swain, S.M.; Whaley, F.S.; Ewer, M.S. Congestive heart failure in patients treated with doxorubicin: A retrospective analysis of three trials. Cancer 2003, 97, 2869-2879. [CrossRef] [PubMed]

54. Aston, W.J.; Hope, D.E.; Nowak, A.K.; Robinson, B.W.; Lake, R.A.; Lesterhuis, W.J. A systematic investigation of the maximum tolerated dose of cytotoxic chemotherapy with and without supportive care in mice. BMC Cancer 2017, 17, 684. [CrossRef]

55. Young, R.C.; Ozols, R.F.; Myers, C.E. The anthracycline antineoplastic drugs. N. Engl. J. Med. 1981, 305, 139-153. [CrossRef]

56. Hodjat, M.; Haller, H.; Dumler, I.; Kiyan, Y. Urokinase receptor mediates doxorubicin-induced vascular smooth muscle cell senescence via proteasomal degradation of TRF2. J. Vasc. Res. 2013, 50, 109-123. [CrossRef] [PubMed]

57. Di Lascio, N.; Stea, F.; Kusmic, C.; Sicari, R.; Faita, F. Non-invasive assessment of pulse wave velocity in mice by means of ultrasound images. Atherosclerosis 2014, 237, 31-37. [CrossRef]

58. Leloup, A.J.; Fransen, P.; Van Hove, C.E.; Demolder, M.; De Keulenaer, G.W.; Schrijvers, D.M. Applanation tonometry in mice: A novel noninvasive technique to assess pulse wave velocity and arterial stiffness. Hypertension 2014, 64, 195-200. [CrossRef]

59. Catterall, W.A. Voltage-gated calcium channels. Cold Spring Harb. Perspect. Biol. 2011, 3, a003947. [CrossRef]

60. Fransen, P.; Van Hove, C.E.; van Langen, J.; Schrijvers, D.M.; Martinet, W.; De Meyer, G.R.; Bult, H. Contribution of transient and sustained calcium influx, and sensitization to depolarization-induced contractions of the intact mouse aorta. BMC Physiol. 2012, 12, 9. [CrossRef]

61. Leloup, A.J.; Van Hove, C.E.; Kurdi, A.; De Moudt, S.; Martinet, W.; De Meyer, G.R.; Schrijvers, D.M.; De Keulenaer, G.W.; Fransen, P. A novel set-up for the ex vivo analysis of mechanical properties of mouse aortic segments stretched at physiological pressure and frequency. J. Physiol. 2016, 594, 6105-6115. [CrossRef] [PubMed] 